\title{
Food Safety and COVID-19: Precautionary Measures to Limit the Spread of Coronavirus at Food Service and Retail Sector
}

\author{
Muhammad Shahbaz ${ }^{1 *}$ (D) Muhammad Bilal $^{2}(\mathbb{D})$, Abdul Moiz $^{3}$ (D), \\ Shagufta Zubair ${ }^{4}$ (D) and Hafiz M.N. Iqbal ${ }^{5}$ iD
}

\begin{abstract}
${ }^{1}$ Mawarid Food Company, Al Wizarat, Riyadh 12622, Saudi Arabia. ${ }^{2}$ School of Life Science and Food Engineering, Huaiyin Institute of Technology, Huaian 223003, China. ${ }^{3}$ Section of Chemical and Food Engineering, Department of Industrial Engineering, University of Salerno, Italy. ${ }^{4}$ Dubai Municipality, United Arab Emirates. ${ }^{5}$ Tecnologico de Monterrey, School of Engineering and Sciences, Campus Monterrey, Ave. Eugenio Garza Sada 2501, Monterrey, N.L., CP 64849, Mexico.
\end{abstract}

\begin{abstract}
Coronavirus pandemic has drastically upended the daily life routines of human beings and has wide wide-ranging effects on entire sectors of society. The food sector is also susceptible and substantially harmed by the influence of intensive effects of coronavirus. To ensure food safety and limit the spread of coronavirus at food services and retail sector has become a challenge where delicate and fresh food items are served and delivered to the customers, which have passed through a series of operational steps from order taking, food receiving, preparation of food, packing, delivery to customers. At each step, there is a possibility of food handlers to touch the food surface or food directly and if food handler is not following appropriate precautionary measures e.g. hand hygiene, sanitization and disinfection, social distances, and is touching, then it can be a possible source of coronavirus spread. Since there is no evidence that food is a coronavirus transmission route but during the food operations, improper sanitization and disinfection of key touchpoints, food contact, nonfood contact, equipment and cleaning tools surfaces and close contact of food handlers with staff and customers not only can put themselves on risk but can also be a risk for customers. Food services and the retail sector should make sure proper hand hygiene, approved sanitizers and disinfectants in use, follow social distances at workstations and while interacting with the customers. Finally, the business should be vigilant to monitor the temperature of staff and incoming guests to identify if there may any sick person to avoid from further spread of coronavirus and shall report to concerned health authorities if anyone symptoms matching with COVID-19
\end{abstract}

Keywords: Coronavirus, COVID-19, Food safety, Preventive measures, Social distances, Personal hygiene, Sanitization, Temperature monitoring

*Correspondence: shahbazfoodtech@gmail.com

(Received: March 26 2020; accepted: April 08 2020)

Citation: Shahbaz M, Bilal M, Moiz A, Zubair S, Iqbal HMN. Food Safety and COVID-19: Precautionary Measures to Limit the Spread of Coronavirus at Food Service and Retail Sector. J Pure Appl Microbiol. 2020;14(suppl 1):749-756. doi: 10.22207/JPAM.14.SPL1.12

(c) The Author(s) 2020. Open Access. This article is distributed under the terms of the Creative Commons Attribution 4.0 International License which permits unrestricted use, sharing, distribution, and reproduction in any medium, provided you give appropriate credit to the original author(s) and the source, provide a link to the Creative Commons license, and indicate if changes were made. 


\section{INTRODUCTION}

The currently available literature, reports, surveys, and news articles are the first signpost that indicates the first appearance of novel Coronavirus (2019-nCoV) cases in workers from the seafood and animal market in Wuhan City, Hubei Province, China. Since then, several epidemiological analyses are being done to clearly and definitively state how the first human case(s) of 2019-nCoV/COVID-19 occurred. However, based on the literature data, it is logical to consider that the on-spot food handlers and other employees were likely exposed unknowingly to 2019-nCoV through handling and slaughtering the infected animals. Though these infected food handlers and employees were not the first-hand consumers on the product being sold in the market, however, direct breathing in the viral particle containing environment may have caused them to get infected unwittingly. Besides that, now considering the global perspective of the 2019nCoV/COVID-19 spread rate, current cases are due to person-to-person transmission at local, regional, national and international levels. Considering such scenarios, it is equally important to highlight the highly requisite precautionary measures to limit or control the spread of 2019-nCoV/COVID-19 via person-to-person transmission at food service and retail sector. Careful consideration of several precautionary measures (Fig. 1) and related symptoms can help to put the current 2019-nCoV/ COVID-19 outbreak in perspective.

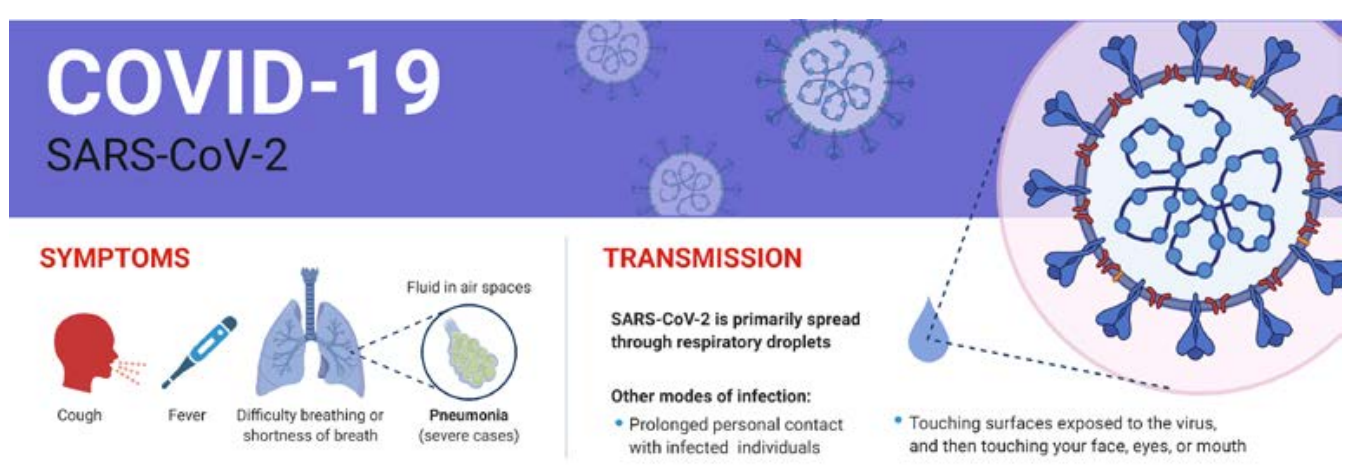

PREVENTION \& SAFETY

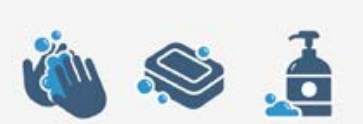

Wash and sanitize your hands frequently

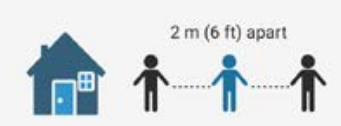

Self-isolate and practice social distancing

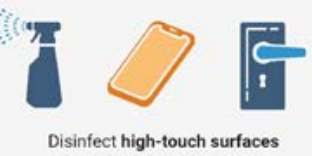

Disinfect high-touch surfaces

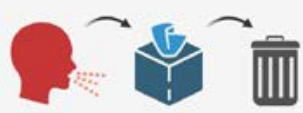

Cough into your elbow or tissues and dispose of tissues right away

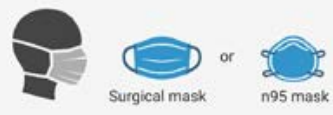

Wear a mask if you're sick or advised to

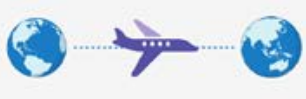

Avoid non-essential and international travel

\section{TREATMENT}

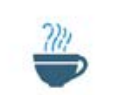

Stay hydrated

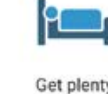

of rest

\section{STAY INFORMED}

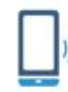

Refer to the WHO, CDC, and your local government for the most up-to-date and accurate information

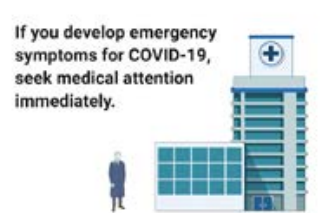

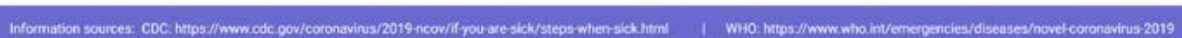

Fig. 1. Safety information and precautionary measures to put the current 2019-nCoV/COVID-19 outbreak in perspective. The Figure was created with the "BioRender.com" template and exported under the terms of premium subscription. 
The 2019-nCoV/COVID-19 transmission via person-to-person at food service and retail sector is another matter, though nothing has reported on this critical aspect, but should not be equally ignored under the current rising situation. This does come under a food safety/food handling issue. Furthermore, individuals infected with the 2019-nCoV virus, whether they are obviously ill or not showing symptoms, will actively shed the virus which can ultimately contaminate the environment, and anything located in that environment, including food products. Personto-person transmission behaviors and the impact of social distancing along with principles of herd immunity are shown in Fig. 2 . The severity of COVID-19 and/or transmissibility of 2019-nCoV, or at least its geographical distribution, seems to be higher and broader than expected ${ }^{1,2}$.

Herein, we aimed to highlight the precautionary measures to limit the 2019-nCoV/ COVID-19 spread in food services and the retail sector. A particular focus is given to the food handlers and employees work in the food and retail sector since workers throughout the food supply chain are at risk. During the ongoing 2019$\mathrm{nCoV/COVID-19}$ pandemic, the food chains will be under pressure to maintain a stable food supply. However, typical working surroundings (unhygienic environment) for food handlers and employees make it difficult to prevent virus transmission is a challenge in these sectors. Policymakers need to assess vulnerabilities and gaps in assistance in all areas of the food supply chain to ensure that both the nation's food supply and its workers are protected. To potentially avoid such undesirable circumstances, the following guidelines are highlighted to further raise awareness in a sophisticated manner.

Precautionary measures to limit the spread of 2019-nCoV/COVID-19

To ensure the safety of foods and to control the spread of coronavirus at food service and retail sector, following precautionary measures can be helpful

\section{Principles of}

\section{HERD IMMUNITY \& SOCIAL DISTANCING}

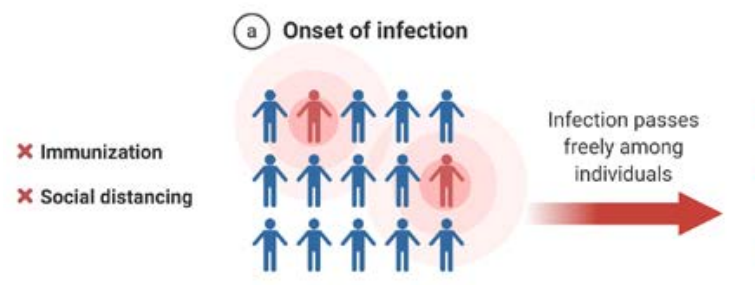

(b) Spread

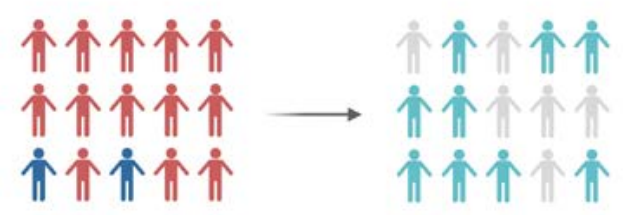

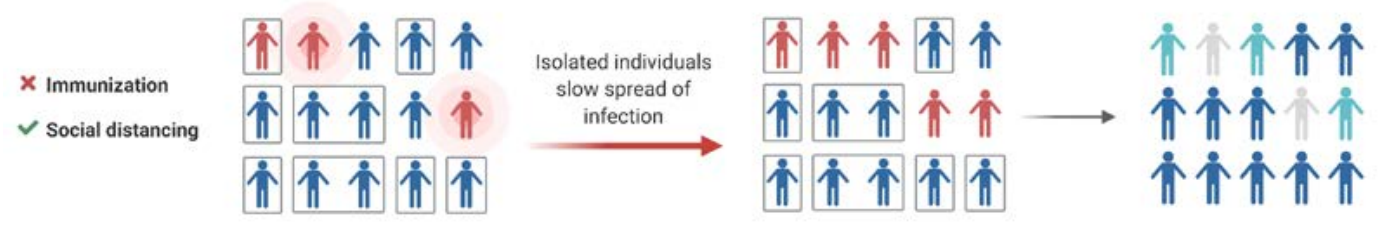
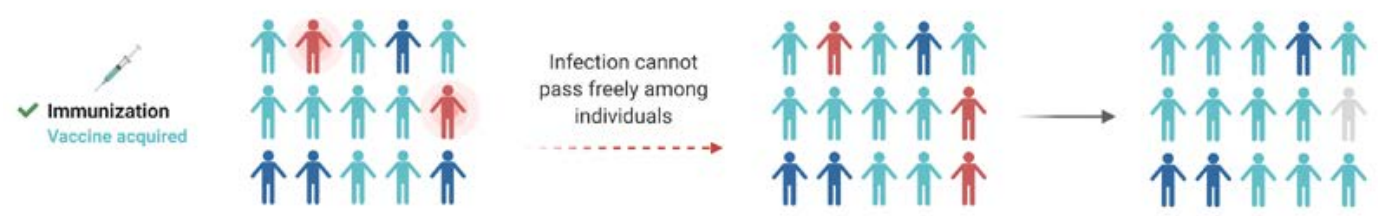

Fig. 2. Person-to-person transmission behaviors and the impact of social distancing along with principles of herd immunity. The Figure was created with the "BioRender.com" template and exported under the terms of premium subscription. 


\section{Hand hygiene practices}

Hands are also one of the most common ways to spread the virus from one person to the next. Food handlers are directly involved in food service operation activities which engage them in touching the food contact (utensils, small ware's, trays, tables), nonfood contact surfaces (door handles, walls, handrails, menues, kiosks, chairs, trash bins, dispensers and equipment surfaces (cooler and freezer handles, dressing and preparation table surfaces, computers, tablets, equipment controllers, buttons, touchpads) and cleaning tools, etc. Germs from unwashed hands can be spread and transferred to other surfaces during food preparations, cooking, storing and serving and then transferred to other food handlers and staff and ultimately to customers as well.

Keeping hands frequently washed and sanitized is the most important and critical steps to evade getting sick and to reduce the spread of the coronavirus during food service operations. COVID-19 directly spread by not washing hands with soap under clean running water up to the specific time of minimum 20 seconds. CDC recommends cleaning hands as per specific instructions to avoid getting sick and to further spread the germ. The food businesses should ensure designated and adequate hands washing facilities are provided and ensure food handlers thoroughly and frequently wash their hands. Handwashing facilities should be equipped with warm running water, normal soap and clean dry paper towels to dry the hands after washing. Hand sanitizers cannot replace handwashing but can be used as an added measure.

Food handlers should follow the instruction on how to wash hands properly as per the $\mathrm{CDC}^{3}$.

- Wet your hands with clean, running water, turn off the tap, and apply a generous amount of soap.

- Lather your hands by rubbing them together with the soap. Make sure to lather the backs of your hands, between your fingers, and under your nails.

- Scrub your hands for at least $20 \mathrm{sec}$.

- Rinse your both hands properly under clean, running water.

- Dry your hands completely using a clean disposable or paper towel or use an air dryer.

- In addition, it is also indispensable for food handlers to maintain the healthy habits in food preparation areas and kitchen to wash hands especially

- After using the restroom and again upon entering back to the kitchen or food preparation area.

- Gloves should be cleaned and changed as necessary, and hands should wash before wearing gloves and after using, to prevent the spread of germs.

- After handling raw meat, poultry, seafood, eggs and before handling ready to eat foods and touching ready to eat food contact surfaces.

- After coughing, sneezing, or blowing your nose.

- $\quad$ After performing nonfood-contact surfaces cleaning tasks e.g. wiping counters, washing or handling uncleaned dishes, brooming, dusting, mopping, handling of trash bins and garbage, cleaning of restrooms or cleaning other surfaces with chemicals.

- Before, during, and after preparing any food or any time when hands become contaminated.

- After touching pets, pet food, or pet treats or after treating cut or wound.

\section{Sanitization and disinfection}

The use of right sanitizer and disinfectant with proper concentration and contact time is key to limit the spread of coronavirus. Before explaining more about where and for how long to use sanitizers and disinfectants, it is imperative to comprehend what sanitizers and disinfectants are. Sanitizers or sanitizing agents are employed to minimize microorganism's loads from the environmental surfaces to a safe level determined by public health codes, ordinances or regulations. Sanitizers are generally used in association with food and food-processing equipment. For instance, there are sanitizers for cooking surfaces, as well as sanitizing rinses for surfaces such as cooking utensils and dishes. Despite somewhat differences, sanitizers and disinfectants are commonly used interchangeably as they both function to killing microorganisms on contact.

Food handlers should make sure to sanitize and disinfectant the following key areas to reduce the spread of coronavirus. 


\section{Food-contact surfaces sanitization}

Direct Food contact surfaces (utensils, small wares, trays, tables, and high-risk infection areas need to be cleaned and sanitized frequently. Coronavirus can be easily killed on these surfaces with the use of sanitizers and disinfectants. Standard sanitization and disinfestation practices are effective and critical in the prevention and limit the spread of coronavirus. All food contact surfaces and items must be cleaned and sanitized after each use and before food handlers begin working with a different type of food. In addition, sanitize and clean these areas when may have contaminated or food handlers are interrupted during the task ${ }^{4}$. If food contact surfaces and items are in continuous use, at least sanitize and clean every $4 \mathrm{~h}$ or preferably every two hours during coronavirus pandemic. Chlorine (as sodium hypochlorite) with a concentration of $50-100 \mathrm{ppm}$ is the low-cost agent most widely used to sanitize food contact surfaces 5 .

\section{Non-food contact surfaces sanitization}

The components of equipment such as seals, doors, fasteners, hinges, and kick plates should be kept intact, tight, and adjusted according to the manufacturer's stipulations and should be frequently sanitized with approved and properly concentrated sanitizer.

\section{Cutting blocks/boards surface sanitization}

Surfaces such as boards and cutting blocks, which are subjected to scoring and scratching shall be resurfaced if they cannot be effectively sanitized and cleaned or discarded if not able to be resurfaced.

\section{Fresh produce sanitization}

In food service and retail sector, fresh vegetables are being received by suppliers, mostly these vegetables are manually cut, and these are washed with clean water or sanitizers before to pack in salad boxes, to display at salad bars or serve to the customers. It is essential to make sure food handlers cut the vegetables with cleaned hands, by using cleaned and sanitized cutting boards and cutting knife and place in sanitized holding containers, utensils or boxes after properly washed and sanitized to limit the spread of coronavirus through surfaces and equipment ${ }^{5}$.

Chlorine (as sodium hypochlorite) with a concentration of $50-100$ ppm is a low-cost agent that is most extensively consumed to disinfect fresh produce ${ }^{6}$. Peracetic acid (PPA) is being promoted in recent years as a viable alternative to chlorine and could be used at a concentration of 150 to $200 \mathrm{ppm}$. The strength of the chlorine or Peracetic acid solution can be checked by commercially available chlorine and peracetic acid test strips.

Utensils and small wares sanitization

For utensils and kitchen small wares, the following two methods can be used for sanitization and need to ensure sanitization is being done with appropriate temperatures and approved chemicals.

Hot water sanitization

In dishwashers or dish machines, the temperature of the fresh hot-water sanitizing rinse as it enters the manifold cannot be more than 90 ${ }^{\circ} \mathrm{C}\left(194^{\circ} \mathrm{F}\right)$, less than $74^{\circ} \mathrm{C}\left(165^{\circ} \mathrm{F}\right)$ in a stationary rack, single-temperature machine or less than $82^{\circ} \mathrm{C}\left(180^{\circ} \mathrm{F}\right)$ in all other high-temperature dish machines and dishwashers. In manual ware, washing equipment basin or three compartmental sinks, the temperature of the water must be at least $77^{\circ} \mathrm{C}\left(171^{\circ} \mathrm{F}\right)$.

Chemicals sanitization

Chemicals including iodine, chlorine, and quaternary ammonium have been approved as potential sanitizing agents for the sanitization of food-contact surfaces in retail and foodservice establishments. The effectiveness of the results of sanitizers depends upon the right concentration, proper temperature range and contact time. Food handlers should be careful while using chemicals for sanitization as too little or too much

Table 1. Chemical sanitizes commonly used in retail/food service establishments.

\begin{tabular}{|c|c|c|}
\hline Chemical Sanitizer & Concentration & Contact Time \\
\hline Quaternary Ammonium Compounds & Follow manufacturer instructions & At least $30 \mathrm{sec}$ \\
\hline Chorine & $50 \mathrm{mg} / \mathrm{L}$ in water between $24^{\circ} \mathrm{C}$ & \\
\hline$\left(75^{\circ} \mathrm{F}\right)$ and $38^{\circ} \mathrm{C}\left(100^{\circ} \mathrm{F}\right)$ & For $7 \mathrm{sec}$ & \\
\hline lodine & Follow manufacturer instructions & At least $30 \mathrm{sec}$ \\
\hline
\end{tabular}


concentration range, improper temperature and contact time not as per Environment Protection Agency (EPA) registered label or manufacturer recommendations can results in an inadequate reduction of microorganisms, destructive to equipment's, toxic and can have the poor sanitizing ability over the time. In general, sanitizers are effective and work well at a temperature between $13^{\circ} \mathrm{C}\left(55^{\circ} \mathrm{F}\right)$ and $49^{\circ} \mathrm{C}\left(120^{\circ} \mathrm{F}\right){ }^{7}$. Table 1 summarizes chemical sanitizes commonly used in retail/food service establishments.

Be sure to use a chemical sanitizer other than iodine, chlorine, or quaternary ammonium following the instructions specified by the EPAregistered label use. Food handlers should confirm the strength and accuracy of the sanitization solution by using approved relevant test kits and strips $^{8}$.

Keeping food handlers and other employees safe by avoiding close contacts

Social distances are very important to help slow the spread of coronavirus and this has been recommended by CDC as well as food safety authorities to keep a space of 2 meters (6.5 feet) at least. It is critically important for food handlers to limit the person to person contact/proximity during operations hours and food preparations inside the kitchen or food preparation areas to prevent the risks of viruses. Walking or crossing someone is unlikely to constitute "close contact." Appropriate Use of Personal Protective Equipments (PPE)

The food handlers and staff workers that handle raw food items such as chicken, milk and fresh vegetables and working in kitchen or food preparation areas should use appropriate protective clothing, gloves, masks, hairnets, and should wash their hands frequently, to avoid touching their face, mouth, eyes, and nose to avoid the spread of coronavirus. The employees should not shake hands among each other and with others during working and during shift changes. Single-use gloves, disposable aprons, hairnets, shoe covers should be disposed of properly once these become damaged or soiled ${ }^{9}$.

\section{Safe Use of Common Tools}

Common tools like mops, brooms, rakes, scrapers, or hand tools should be sanitized after each use, especially between two separate users. The handheld temp probes should also sanitize before and end of each task.

The business should provide personal pens and order taking pads separately to order takers, other staff should sanitize their pens at least once per shift.

Common use computers, tablets or touch screens should also be sanitized between users.

Safe Shift Changing, Locker Rooms, On the Job Coaching/Training Sessions and Employee Clock in/Outs

Avoid gathering and crowd during shift changes and breaks and if possible, reduce the time to a minimum for change shifts/handovers and stop additional breaks, e.g., tea breaks.

Identify individuals that do not need to come into restaurant restrooms and do not need to be using the same resources as the larger number of employees. Divide all teams into smaller groups and isolate them to separate bathrooms and break areas as possible.

Prefer to use text/what up messages, chats, free conference calling or phone calls during shift changes to prevent face-to-face contact and to bring teams together remotely.

Avoid touching or kept to minimum nonselected uniform clothing and hangers in lockers. Place the now empty hanger on a different rack to avoid the hanger touching clean uniforms and from other employees handling the previously touched hanger

Employees should also avoid touching clock in and out machines or provide additional sanitizer near the machine.

The supervisors should make use of a camera from another room to clock employees in/out or preferably should handle by entering on registers or attendance sheets. The employees should avoid gathering and crowd during on the job coaching and training sessions and should advise the team to at least keep 2 meters (6.5 feet) distance ${ }^{10}$.

\section{Keeping customers safe}

The health and wellbeing of customers are the top priority for the businesses. As the situation develops, dine-in sections are closed and only online ordering, take away and even contactless deliveries are encouraged. To keep the business on track and customers safe it is now necessary for business operators to reach out to customers through websites and apps. In 
addition, food service business should follow the following instruction to keep customers safe from coronavirus $^{11,12}$.

- Increase the number of hand-sanitizer dispensers at entrances and in the waiting areas of their restaurants.

- $\quad$ Always sanitize and disinfect trays, dining room tables and chairs after each use.

- Increase the frequency of cleaning and sanitizing high-touch surfaces such as doors, kiosks, touch screens, restrooms and more.

- Take customer orders by phone or in person.

- Manage the crown and urge the customers to maintain social distance during peak hours. It is better to put the signs.

- $\quad$ Employees must fill all beverages. No self-service beverages or customer refills.

- $\quad$ Say customers not to share food, drink or utensils particularly in the current situation.

- $\quad$ Give single-use items like napkins and condiments directly to the customer instead of putting them in a self-service area.

- $\quad$ Provide wrapped products to customers.

- $\quad$ Avid handling money and Banknotes, which may be spreading the new coronavirus, encourage using contactless payments if possible. If food workers must handle money, it is important to wash hands afterward and always before handling food.

- $\quad$ Follow HSE guidance on social distancing when picking up deliveries and passing deliveries to customers.

- $\quad$ Sanitize hands before and after each delivery transaction

Temperature monitoring and screening

The retail and food services sector should encourage their staff to implement temperature monitoring and screening by trained personnel by using calibrated thermometer guns and noncontact or forehead infrared thermometers during the start of each shift and then every 4 hours during their job. In most adults, Fever is if the temperature is $100.4^{\circ} \mathrm{F} / 38^{\circ} \mathrm{C}$ or higher.
The businesses should review and revise sick leave policies as needed to support their staff to ensure they can take time off if they get ill or need to take care of a sick family member. They should have enough time to fully recover from COVID-19. This may be up to 14 days.

Food service operators and food handlers who are possibly sick with the symptoms matching COVID-19 should stay home. All those employees with family members or caregivers with symptoms matching COVID-19 should also stay home until full recovery.

Staff and managers with coughing, shortness of breath, fever, or other symptoms of illness should not return to work until they are symptom-free.

Any food handler who is running a fever, cough or exhibits other abnormal symptoms, staff and managers should help them to contact medical services. Those who refuse to have their temperature check should report to management to stop or remove him/her from work to save other staff members.

The team who come to work ill or become ill while at work should send back home immediately to minimize the risk of contamination to food, customers and other food handlers and staff members. If any food worker has tested positive for COVID-19, the food businesses should report to the health care department and follow their advice ${ }^{13}$.

\section{ACKNOWLEDGMENTS}

All listed author(s) are thankful to their representative universities/institutes for providing the related support to compile this work.

\section{CONFLICT OF INTEREST}

The listed author(s) declare no conflict of interest in any capacity, including competing or financial.

\section{AUTHORS' CONTRIBUTION}

All listed author(s) have made a substantial, direct and intellectual contribution to the work, and approved it for publication.

\section{FUNDING}

None. 


\section{ETHICS STATEMENT}

This article does not contain any studies with human participants or animals performed by any of the authors.

\section{AVAILABILITY OF DATA}

Not applicable.

\section{REFERENCES}

1. Bilal M, Nazir MS, Parra-Saldivar R, Iqbal HM. 2019-nCoV/COVID-19 - Approaches to viral vaccine development and preventive measures. J Pure Appl Microbiol. 2020;14(1):25-29. Article 6146. https://doi.org/10.22207/JPAM.14.1.05. https://doi. org/10.22207/JPAM.14.1.05

2. Iqbal HMN, Romero-Castillo KD, Bilal M, ParraSaldivar R. The Emergence of Novel-Coronavirus and its Replication Cycle -An Overview. J Pure Appl Microbiol. 2020;14(1):13-16. Article 6146. https://doi.org/10.22207/JPAM.14.1.03. https://doi. org/10.22207/JPAM.14.1.03

3. Handwashing: A Healthy Habit in the Kitchen. Available online at: https://www.cdc.gov/handwashing/ handwashing-kitchen.html [Last accessed: 6 April 6, 2020].

4. 3 tips to ensure clean and sanitary food-contact surfaces. Available online at: https://www.restaurant. org/Articles/Operations/3-tips-sanitary-food-contactsurfaces. [Last accessed: 6 April 6, 2020].

5. Sapers GM. Efficacy of washing and sanitizing methods for disinfection of fresh fruit and vegetable products. Food Technology and Biotechnology. 2001;39(4). Publication \#127846

6. Suslow T.. Chlorination in the production and postharvest handling of fresh fruits and vegetables. Fruit and Vegetable Processing. 2000; Chapter 6:2-15.

7. Fraser AM, Pascall MA. Cleaning and sanitization of food-contact surfaces in retail/food service establishments. 2010. Available online at: $h t t p: / / w w w$. foodsafetymagazine.com. [Last accessed: 6 April 6, 2020].

8. https://www.fda.gov/media/110822/download. [Last accessed: 6 April 6,2020$]$.

9. https://www.fsai.ie/faq/coronavirus.html. [Last accessed: 6 April 6, 2020].

10. Coronavirus resources for our industry. Available online at: https://affifoodsafety.org/coronavirus/ [Last accessed: 6 April 6, 2020].

11. https://www.washingtonpost.com/news/voraciously/ wp/2020/03/10/heres-what-you-need-to-knowabout-dining-out-in-the-age-of-coronavirus/ [Last accessed: 6 April 6, 2020].

12. https://www.telegraph.co.uk/news/2020/03/02/ exclusive-dirty-banknotes-may-spreading-coronavirusworld-health/?subld3=xid:fr1585602517573ccb). [Last accessed: 6 April 6, 2020].

13. COVID-19: Hotels conduct temperature screenings of guests, staff, ramp up safety measures. Available at: https://economictimes.indiatimes.com/industry/ services/hotels-/-restaurants/covid-19-hotelsconduct-temperature-screenings-of-guests-stafframp-up-safety-measures/articleshow/74587219. cms?from=mdr [Last accessed: 6 April 6, 2020]. 